\title{
Corrosão
}

\section{Investigação do efeito do teor de intersticiais sobre o grau de sensitização em aços inoxidáveis ferríticos a $600^{\circ} \mathrm{C}$}

\author{
Carlos Augusto Serna-Giraldo \\ Doutorem Engenharia Metalúrgica pela EPUSP.E-mail: caserna@usp.br \\ Cristiane Reis Ide \\ Aluna de Graduação em Engenharia de Materiais da EPUSP.E-mail: cristiane.ide@poli.usp.br \\ Rodrigo Magnabosco \\ Professor Doutor do Centro Universitário da FEl.E-mail: rodrmagn@fei.edu.br \\ Clarice Terui Kunioshi \\ Doutora em Ciência e Tecnologia Nuclear-Materiais pelo IPEN/CNEN-SP \\ E-mail: clarice.kunioshi@poli.usp.br \\ Neusa Alonso-Falleiros \\ Professora Doutora da EPUSP.E-mail:neusa.alonso@poli.usp.br
}

\section{Resumo}

O objetivo do presente trabalho foi investigar o efeito do teor de carbono e nitrogênio em aços inoxidáveis ferríticos com $17 \% \mathrm{Cr}(16 \% \mathrm{Cr}-0,04 \% \mathrm{C}-0,032 \% \mathrm{~N}$; $17,2 \% \mathrm{Cr}-0,02 \% \mathrm{C}-0,0062 \% \mathrm{~N} ; 18,5 \% \mathrm{Cr}-0,008 \% \mathrm{C}-$ $0,0213 \% \mathrm{~N}$ ) sobre o grau de sensitização (GS). Os aços foram solubilizados a $1200^{\circ} \mathrm{C}$ e resfriados em água. Tratamentos isotérmicos foram realizados a $600^{\circ} \mathrm{C}$ entre $5 \mathrm{mi}$ nutos e 16 horas. Foi realizado o ensaio de reativação eletroquímica potenciodinâmica de ciclo duplo (DL-EPR) em solução $0,5 \mathrm{M} \mathrm{H}_{2} \mathrm{SO}_{4}$ a $(25 \pm 2)^{\circ} \mathrm{C}$. O GS foi medido através da relação entre as densidades de correntes anódicas máximas nas etapas de reversão, $\boldsymbol{i}_{\boldsymbol{r}}$, e ativação, $\boldsymbol{i}_{\boldsymbol{a}}$. $\mathrm{O}$ exame microestrutural dos corpos-de-prova foi realizado nos microscópios óptico e eletrônico de varredura após ataque metalográfico com reagente Vilella. Os resultados mostram variação do GS com o tempo. Um máximo de GS foi obtido para cada aço e, posteriormente, foi observada diminuição do GS. A intensidade do GS e o tempo de ocorrência variaram em função dos teores de carbono e nitrogênio nos aços.

Palavras-chave: Aços inoxidáveis ferríticos, corrosão intergranular, sensitização, técnicas eletroquímicas potenciodinâmicas.

\begin{abstract}
The purpose of this work was to investigate the effect of carbon and nitrogen in $17 \% \mathrm{Cr}$ ferritic stainless steels (16\%Cr-0.04\%C-0.032\%N; $17.2 \% \mathrm{Cr}-0.02 \% \mathrm{C}-$ $0.0062 \% \mathrm{~N} ; 18.5 \% \mathrm{Cr}-0.008 \% \mathrm{C}-0.0213 \% \mathrm{~N})$ on the degree of sensitization (DOS). These steels were solution annealed at $1200^{\circ} \mathrm{C}$ and quenched in water. Isothermal treatments were carried out at $600^{\circ} \mathrm{C}$ between 5 minutes and 16 hours. The Double Loop Electrochemical Potentiokinetic Reactivation test (DL-EPR) was carried out in a $0.5 \mathrm{M} \mathrm{H}_{2} \mathrm{SO}_{4}$ solution at $(25 \pm 2)^{\circ} \mathrm{C}$. The DOS was evaluated using a ratio between maximum anodic current density in reversion, $\boldsymbol{i}_{r}$, and activation, $\boldsymbol{i}_{a}$. The microstructural examination of specimens was carried out using optical and scanning electron microscopy after metallographic etching with Vilella's reagent. The results showed a DOS variation with time. Maximum values of DOS were obtained for each steel, followed by its reduction. The intensity of DOS and its kinetics vary in function of the carbon and nitrogen content in steels.
\end{abstract}

Keywords: Ferritic stainless steel, intergranular corrosion, sensitization, electrochemical reactivation potentiokinetic test. 
Investigação do efeito do teor de intersticiais sobre o grau de sensitização em aços inoxidáveis...

\section{Introdução}

Existe um grande número de evidências experimentais que sustentam a teoria de empobrecimento no teor de cromo como a principal causa de corrosão intergranular em aços inoxidáveis ferríticos (Bond, 1969; Demo, 1971; Frankental, Pickering, 1973; Lee et alii, 1985; Streicher, 1973). Nesses materiais, resfriamentos rápidos até a temperatura ambiente, a partir de $900^{\circ} \mathrm{C}$, não impedem a precipitação de carbonetos e/ ou nitretos ricos em cromo nos contornos de grão. Ao redor desses precipitados, são formadas regiões pobres em cromo, as quais, se não atingem o teor mínimo de cromo (12\%) para produzir passividade, podem ser atacadas por meios agressivos e produzir corrosão intergranular. Essa condição é, normalmente, denominada sensitização e pode ocorrer durante processamentos termomecânicos ou por soldagem.

Dos elementos de liga presentes nos aços inoxidáveis ferríticos, o carbono é o elemento mais importante relacionado com a resistência à corrosão intergranular. Teores de 0,01\%C são suficientes para produzir sensitização nesses aços (Folkhard, 1988). Nesse sentido, pode se pensar que, diminuindo o teor de carbono, o aço apresente maior resistência à corrosão intergranular. No entanto, trabalhos encontrados na literatura reportam que aços inoxidáveis ferríticos, com baixos teores de elementos intersticiais, são susceptíveis à severa corrosão intergranular (Bond, 1969; Arai et alii, 1987; Tullmin et alii, 1990). Além disso, reduzir o teor de elementos intersticiais em níveis inferiores a seus limites de solubilidade resultaria em uma práti- ca economicamente inviável (Gordon, Van Bennekom, 1996). A sensitização também pode ser reduzida, adicionando elementos estabilizadores, tais como titânio, nióbio e/ou zircônio. Esses elementos formam carbonetos e/ou nitretos mais estáveis, em elevadas temperaturas, que os carbonetos e/ou nitretos de cromo, reduzindo, apreciavelmente, a sensitização (Tomari et alii, 1982; Ogwu, Davies, 1997).

Os tratamentos térmicos, por outro lado, melhoram a resistência à corrosão intergranular dos aços inoxidáveis ferríticos. Esses tratamentos são, normalmente, especificados entre $650^{\circ} \mathrm{C}$ e $800^{\circ} \mathrm{C}$ (Villafuerte, Kerr, 1992). Nessas temperaturas, a velocidade de difusão do cromo na ferrita é, suficientemente, elevada para permitir sua difusão, homogeneizando as regiões empobrecidas. Na faixa de temperaturas entre $500^{\circ} \mathrm{C}$ e $650^{\circ} \mathrm{C}$, a velocidade de difusão do cromo é reduzida (Demo, 1971), sendo, portanto, necessários maiores tempos de tratamento para se recuperar a resistência à corrosão intergranular.

O presente trabalho tem como objetivo estudar o efeito dos elementos intersticiais, carbono e nitrogênio, na resistência à corrosão intergranular de aços inoxidáveis ferríticos com teores de $17 \% \mathrm{Cr}$, após tratamento isotérmico a $600^{\circ} \mathrm{C}$.

\section{Materiais e métodos}

A Tabela 1 apresenta a composição química dos aços estudados. Nota-se, principalmente, os diferentes teores de elementos intersticiais, carbono e nitrogênio.
Os aços foram solubilizados a $1200^{\circ} \mathrm{C}$ por 20 minutos, seguido de resfriamento rápido em água. Posteriormente, foram realizados tratamentos isotérmicos a $600^{\circ} \mathrm{C}$ por tempos de $5,10,20,40$ e 90 minutos e 2, 3, 4, 8 e 16 horas. Foi utilizado forno tubular marca LINDBERG com controle de temperatura por relê de estado sólido. Os tratamentos térmicos foram realizados a vácuo, para evitar a excessiva oxidação das amostras.

Todas as amostras, após tratamentos térmicos, foram lixadas em todas suas faces até lixa \#600, embutidas em baquelite e feito furo para rosca, por onde ocorre o contato elétrico necessário nos ensaios eletroquímicos. Os ensaios foram realizados em galvanostato/potenciostato PAR (Princenton Applied Research) modelo 273A. O controle dos parâmetros de ensaio e o registro dos resultados foram feitos com auxílio do programa "Model 342 Softcorr Corrosion Software v.3.2” instalado em micromputador acoplado ao potenciostato.

O ensaio de reativação eletroquímica potenciodinâmica de ciclo duplo (DL-EPR) foi realizado em, aproximadamente, $700 \mathrm{~mL}$ de solução $0,5 \mathrm{M} \mathrm{H}_{2} \mathrm{SO}_{4}$ a $(25 \pm 2)^{\circ} \mathrm{C}$. A solução foi preparada com água destilada e deionizada e com reagente padrão analítico. Como eletrodo de referência, foi utilizado o eletrodo de calomelano saturado (ECS) e, como contra-eletrodo, um fio de platina. Os corpos-de-prova, previamente lixados até lixa \#600, foram imersos na solução, onde permaneceram por 5 minutos antes do início da polarização, permitindo a estabilização do potencial de corrosão. Os corpos-de-prova foram, posteriormente, polarizados anodicamente até $500 \mathrm{mV}_{\mathrm{ECS}}$,

Tabela 1 - Composição química de aços inoxidáveis ferríticos. O aço com 16\%Cr foi doação da Acesita S.A. e os outros dois foram elaborados na Universidade de Hokkaido-Japão.

\begin{tabular}{c|c|c|c|c|c|c|c|c}
\hline Identificação & $\% \mathbf{C}$ & $\% \mathbf{N}$ & $\% \mathbf{C r}$ & $\% \mathbf{N i}$ & $\% \mathbf{S i}$ & $\% \mathbf{M n}$ & $\% \mathbf{P}$ & $\% \mathbf{S}$ \\
\hline $\mathbf{C r}-\mathbf{C}-\mathbf{N}$ & 0,04 & 0,032 & 16 & 0,23 & 0,32 & 0,37 & 0,033 & 0,0065 \\
\hline $\mathbf{C r}-\mathbf{C}$ & 0,02 & 0,0062 & 17,2 & 0,71 & 0,2 & 0,21 & 0,02 & 0,02 \\
\hline $\mathbf{C r}-\mathbf{N}$ & 0,008 & 0,0213 & 18,5 & ---- & $<0,01$ & 0,021 & 0,003 & 0,004 \\
\hline
\end{tabular}


potencial onde o material encontra-se passivo, e, imediatamente, iniciada a reversão. Tanto na ativação quanto na reativação, a velocidade de varredura empregada foi de 1,67 mV/s. Finalizado o ensaio, foram lidos, diretamente do programa, os valores das máximas densidades de corrente nas etapas de reversão, $\boldsymbol{i}_{r}$, e de ativação, $\boldsymbol{i}_{a}$. O grau de sensitização foi medido através do quociente $\mathbf{i}_{r} / \boldsymbol{i}_{a}$. Os ensaios foram repetidos no mínimo 6 vezes.

O exame microestrutural foi realizado em microscópios óptico e eletrônico de varredura (MEV) marca Philips XL-30, após ensaio DL-EPR e ataque metalográfico com reagente Vilella (1 g de ácido pícrico, $5 \mathrm{~mL}$ de $\mathrm{HCl}$ e $100 \mathrm{~mL}$ de etanol), a fim de se observarem a forma e a distribuição dos precipitados presentes, após tratamento isotérmico.

\section{Resultados e discussão}

A Figura 1 apresenta uma curva típica obtida após ensaio DL-EPR para o aço $\mathrm{Cr}-\mathrm{N}$ solubilizado e tratado isotermicamente a $600^{\circ} \mathrm{C}$ por 40 minutos. Observa-se que, na ascensão do potencial, o material apresenta máxima densidade de corrente, $\boldsymbol{i}_{a}$, em, aproximadamente, $-460 \mathrm{mV}_{\mathrm{ECS}}$ e, posteriormente, sofre passivação. Muitas das curvas apresentaram, na ascensão do potencial, o surgimento de um segundo máximo de densidade de corrente anódica, $\boldsymbol{i}_{2 \text { máx }}$ o qual também pode ser atribuído à presença de regiões pobres em cromo, entre outras causas (Alonso-Falleiros et alii, 1999). Após atingir $500 \mathrm{mV}_{\mathrm{ECS}}$, foi realizada a reversão até o potencial de corrosão. Durante a reativação, as regiões pobres em cromo são atacadas, gerando a densidade de corrente de reativação, $\boldsymbol{i}_{\boldsymbol{r}}$, a qual representa a quantidade de região pobre em cromo. O valor de $\boldsymbol{i}_{r}$ varia, sensivelmente, com o tempo de tratamento isotérmico (Serna-Giraldo, 2006).

A partir dos ensaios DL-EPR, foram determinados os valores de grau de sensitização (GS) - Tabelas 2 e 3.

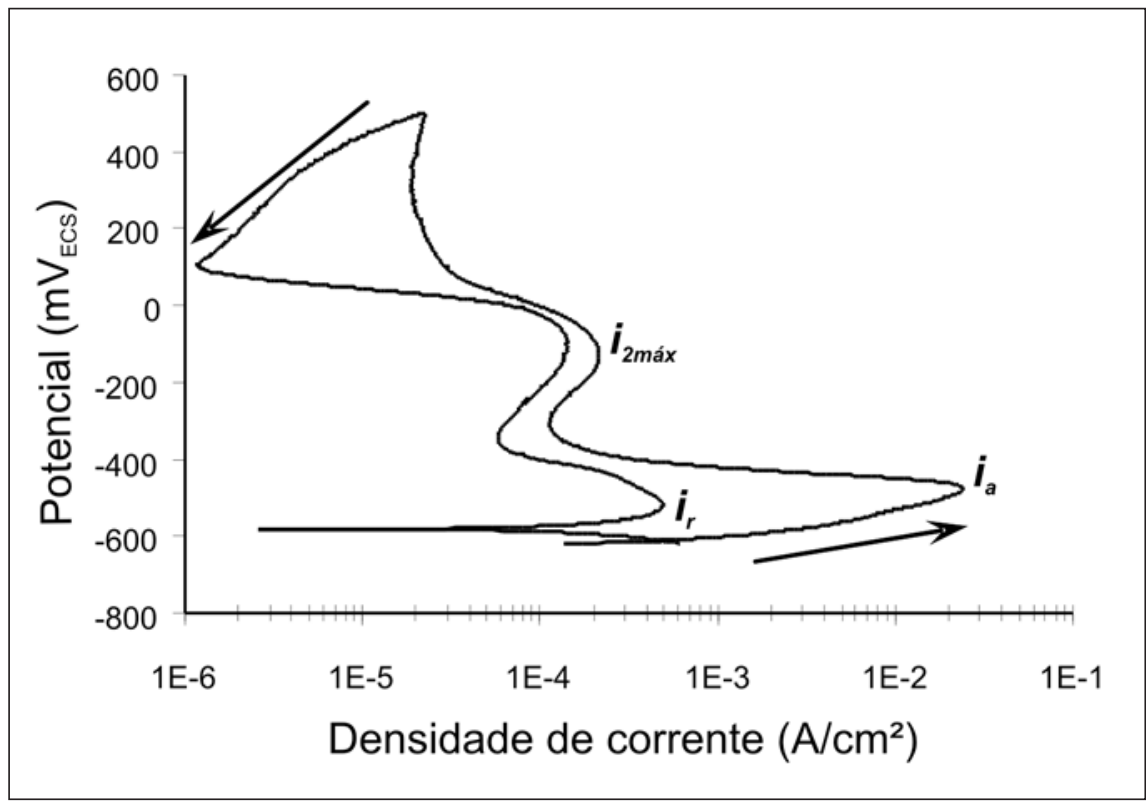

Figura 1 - Curva DL-EPR para o aço $\mathrm{Cr}-\mathrm{N}$ solubilizado e tratado a $600^{\circ} \mathrm{C}$ por 40 minutos.

Tabela 2 - GS após solubilização a $1200^{\circ} \mathrm{C}$ e resfriamento em água (aproximadamente $\left.23^{\circ} \mathrm{C}\right)$.

\begin{tabular}{c|c}
\hline Aço inoxidável ferrítico & $\boldsymbol{i}_{\boldsymbol{r}} \mathbf{i}_{\mathbf{a}}$ \\
\hline Cr-C-N & $0,0030 \pm 0,0032$ \\
\hline Cr-C & $0,0013 \pm 0,0017$ \\
\hline Cr-N & $0,0006 \pm 0,0001$ \\
\hline
\end{tabular}

Tabela 3 - GS após tratamento isotérmico a $600^{\circ} \mathrm{C}$.

\begin{tabular}{c|c|c|c}
\hline Tempo & Cr-C-N & Cr-C & Cr-N \\
\hline 5 minutos & $0,0062 \pm 0,0015$ & $0,0002 \pm 0,0004$ & $0,0014 \pm 0,0004$ \\
\hline 10 minutos & $0,0221 \pm 0,0069$ & $0,0276 \pm 0,0016$ & $0,0074 \pm 0,0030$ \\
\hline 20 minutos & $0,0312 \pm 0,0071$ & $\mathbf{0 , 0 4 8 2} \pm \mathbf{0 , 0 0 3 6}$ & $0,0075 \pm 0,0036$ \\
\hline 40 minutos & $0,0692 \pm 0,0201$ & $0,0267 \pm 0,0105$ & $\mathbf{0 , 0 2 5 2} \pm \mathbf{0 , 0 0 4 2}$ \\
\hline 90 minutos & $\mathbf{0 , 0 9 4 9} \pm \mathbf{0 , 0 2 1 5}$ & $0,0042 \pm 0,0015$ & $0,0167 \pm 0,0055$ \\
\hline 2 horas & $0,02334 \pm 0,0078$ & $0,0016 \pm 0,0005$ & $0,0033 \pm 0,0038$ \\
\hline 3 horas & $0,0163 \pm 0,0190$ & $0,0075 \pm 0,0065$ & $0,0023 \pm 0,0032$ \\
\hline 4 horas & $0,0060 \pm 0,0059$ & $0 \pm 0$ & $0,0024 \pm 0,0030$ \\
\hline 8 horas & $0,0102 \pm 0,0048$ & $0,0051 \pm 0,0055$ & $0 \pm 0$ \\
\hline 16 horas & $0,0044 \pm 0,0032$ & $0,0030 \pm 0,0091$ & $0,0004 \pm 0,0007$ \\
\hline
\end{tabular}


Observa-se que o aço $\mathrm{Cr}-\mathrm{C}-\mathrm{N}$, o qual tem maiores teores de carbono e nitrogênio na sua composição química (Tabela 1), também apresenta maior valor de GS, seguido do aço com Cr-C e, por último, o aço Cr-N. Essa diferença de valores de GS pode ser atribuída, principalmente, à influência do carbono e é justificada a partir dos precipitados formados nos contornos de grão. A Figura 2 , após ataque metalográfico com reagente Vilella, mostra que, durante o resfriamento, a partir da temperatura de solubilização do aço Cr-N, ocorreu fina precipitação nos contornos de grãos ferríticos. Micrografias similares à da Figura 2 também foram observadas para os demais aços após solubilização, apresentando estruturas completamente ferríticas. A diferença de composição química dos aços pode gerar, em função dos teores de carbono e nitrogênio, diferentes tipos de precipitados, tais como carbonetos, nitretos ou carbonitretos de cromo (Jack, Jack, 1973), os quais, por sua vez, gerariam diferentes regiões empobrecidas em cromo e, por conseguinte, diferentes valores de GS.

Os tratamentos isotérmicos realizados a $600^{\circ} \mathrm{C}$ geraram diferentes valores de GS (Tabela 3). Esses valores foram utilizados para elaborar o gráfico da Figura 3. A variação do GS contra o tempo apresenta um comportamento semelhante: inicialmente é observado aumento gradativo no GS, o qual atinge um valor máximo, em tempos diferentes para cada aço e, posteriormente, observa-se diminuição no GS com o aumento no tempo de tratamento isotérmico. Esse comportamento é consistente com o reportado para outros aços inoxidáveis (AlonsoFalleiros et alii, 1999; Teodoro, Wolynec, 1998).

O aumento no GS é devido à precipitação de fases ricas em cromo e subseqüente formação de regiões pobres nesse elemento. A Figura 4 apresenta micrografias típicas, observadas em MEV, para o aço com $\mathrm{Cr}-\mathrm{N}$, após tratamento isotérmico a $600^{\circ} \mathrm{C}$ por diferentes tempos. Observa-se que o material apresenta nova precipitação, ao lado dos precipitados

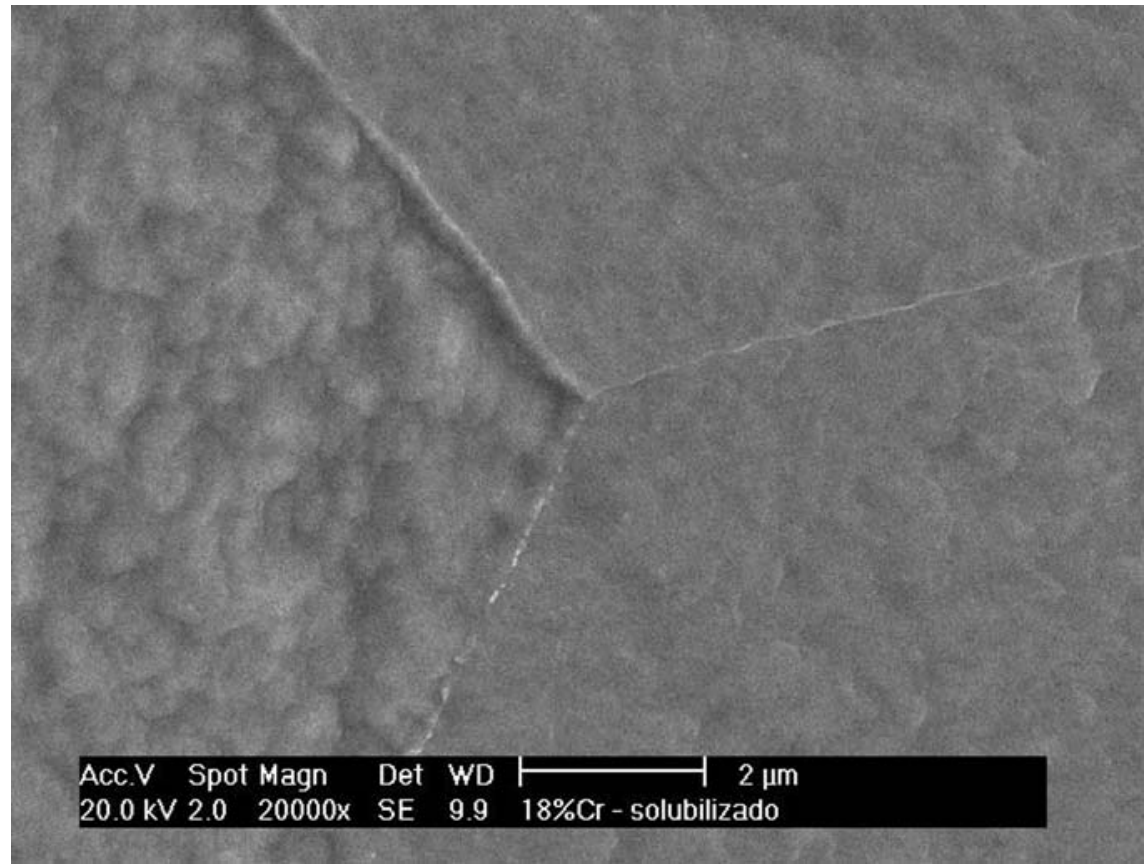

Figura 2 - Micrografia mostrando finos precipitados formados nos contornos de grão ferrítico no aço $\mathrm{Cr}-\mathrm{N}$, após tratamento térmico de solubilização. Ataque metalográfico: Vilella. (MEV).

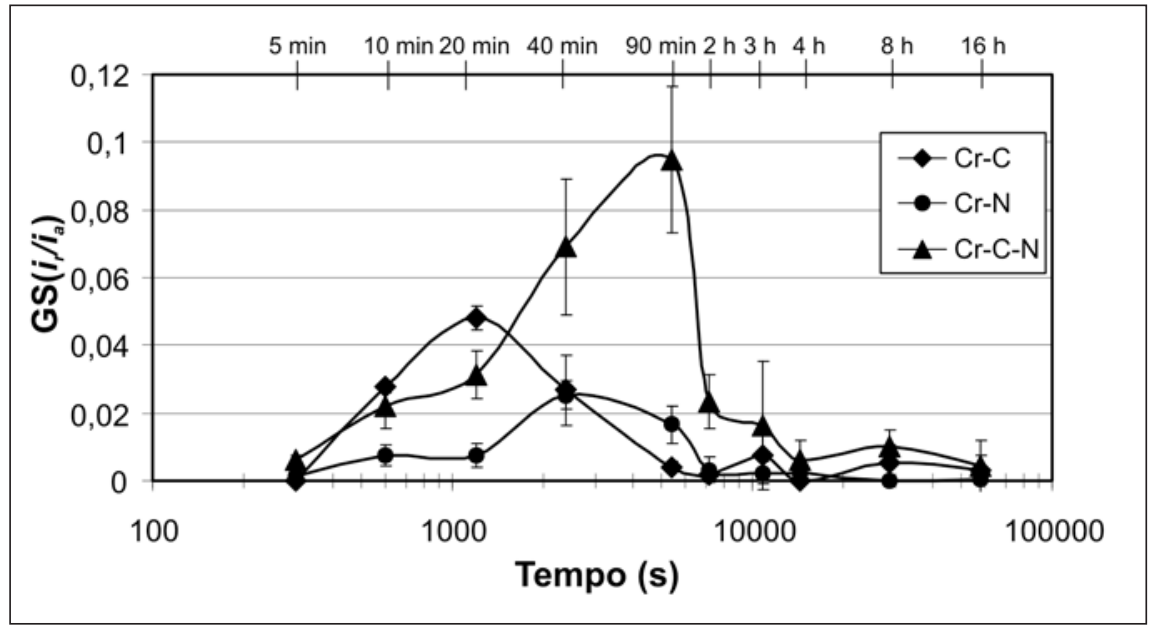

Figura 3 - Variação do grau de sensitização após tratamento isotérmico a $600^{\circ} \mathrm{C}$ por diferentes tempos para os três aços pesquisados.

formados, inicialmente, durante o resfriamento da solubilização (Figura 2). Em 20 minutos, são observados precipitados nos contornos de grão. Essa quantidade precipitada aumenta com o tempo de tratamento isotérmico, como pode ser observado para os tempos de 40 e 90 minutos. Em 2 horas, observa-se que os precipitados apresentam a mesma aparência dos precipitados observados nos tempos anteriores. Por último, observase, em 16 horas, significativa mudança na morfologia e distribuição dos precipitados, os quais se caracterizam por serem mais grosseiros e descontínuos (resultado do coalescimento).

Os precipitados formados após tratamento isotérmico a $600^{\circ} \mathrm{C}$ mostram correlação com o aumento no GS. Resultados similares foram obtidos por SernaGiraldo (2006) para o aço inoxidável ferrítico UNS S43000, após tratamentos isotérmicos entre $500^{\circ} \mathrm{Ce} 700^{\circ} \mathrm{C}$. 
Observa-se, na Figura 3, que os aços com menores teores de carbono e nitrogênio (aços Cr-C e Cr-N) apresentam cinética de sensitização mais rápida, comparativamente ao apresentado pelo aço Cr-C-N. Esse fato confirma as informações da literatura (Bond, 1969; Arai et alii, 1987), as quais mencionam que, diminuindo o teor de elementos intersticiais, não se melhora, significativamente, a resistência à corrosão intergranular dos aços inoxidáveis ferríticos. $\mathrm{O}$ aço $\mathrm{Cr}-\mathrm{C}$ $(0,02 \% \mathrm{C}$ e 0,0062\%N) apresenta máximo GS em 20 minutos, enquanto que os aços Cr-N $(0,008 \%$ C e $0,0213 \% N)$ e Cr-C-N $(0,040 \% \mathrm{C}$ e $0,032 \% \mathrm{~N})$ apresentam esse máximo em 40 e 90 minutos, respectivamente. Por outro lado, a derivada da curva GS, em função do tempo, no trecho de recuperação, é maior para o aço com elevado teor de intersticiais, o que torna o tempo de tratamento para recuperação o mesmo, independente dos teores de carbono e nitrogênio; esse comportamento é uma evidência de que a recuperação é controlada pela difusão de cromo, não dependendo dos teores de intersticiais.

Outro fato importante a se considerar é quanto à intensidade do GS obtido para cada aço, a qual parece ser diretamente proporcional ao teor de carbono e não tanto assim ao teor de nitrogênio. O aço Cr-C-N apresenta, praticamente, o dobro do valor de GS do aço Cr-C, o qual, por sua vez, também apresenta o dobro do GS do apresentado pelo aço Cr-N. Os precipitados formados, durante os tratamentos isotérmicos, seriam, principalmente, carbonetos de cromo tipo $\mathrm{Cr}_{23} \mathrm{C}_{6}$, o qual gera maior empobrecimento em cromo que o nitreto de cromo $\mathrm{Cr}_{2} \mathrm{~N}$ (Streicher, 1973).

Sabe-se que o processo de precipitação e sensitização é controlado pela difusão do cromo. Nesse sentido, a $600^{\circ} \mathrm{C}$, a velocidade de difusão do cromo, em aços inoxidáveis ferríticos, com

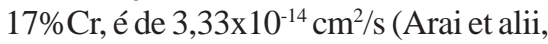
1987), enquanto que a difusão do carbono e do nitrogênio são $3,27 \times 10^{-7} \mathrm{~cm}^{2} / \mathrm{s}$ e $1,87 \times 10^{-7} \mathrm{~cm}^{2} / \mathrm{s}$, respectivamente (Honeycombe, 1982). A partir da composição química (Tabela 1 ), nota-se que os aços apresentam ligeira variação no teor
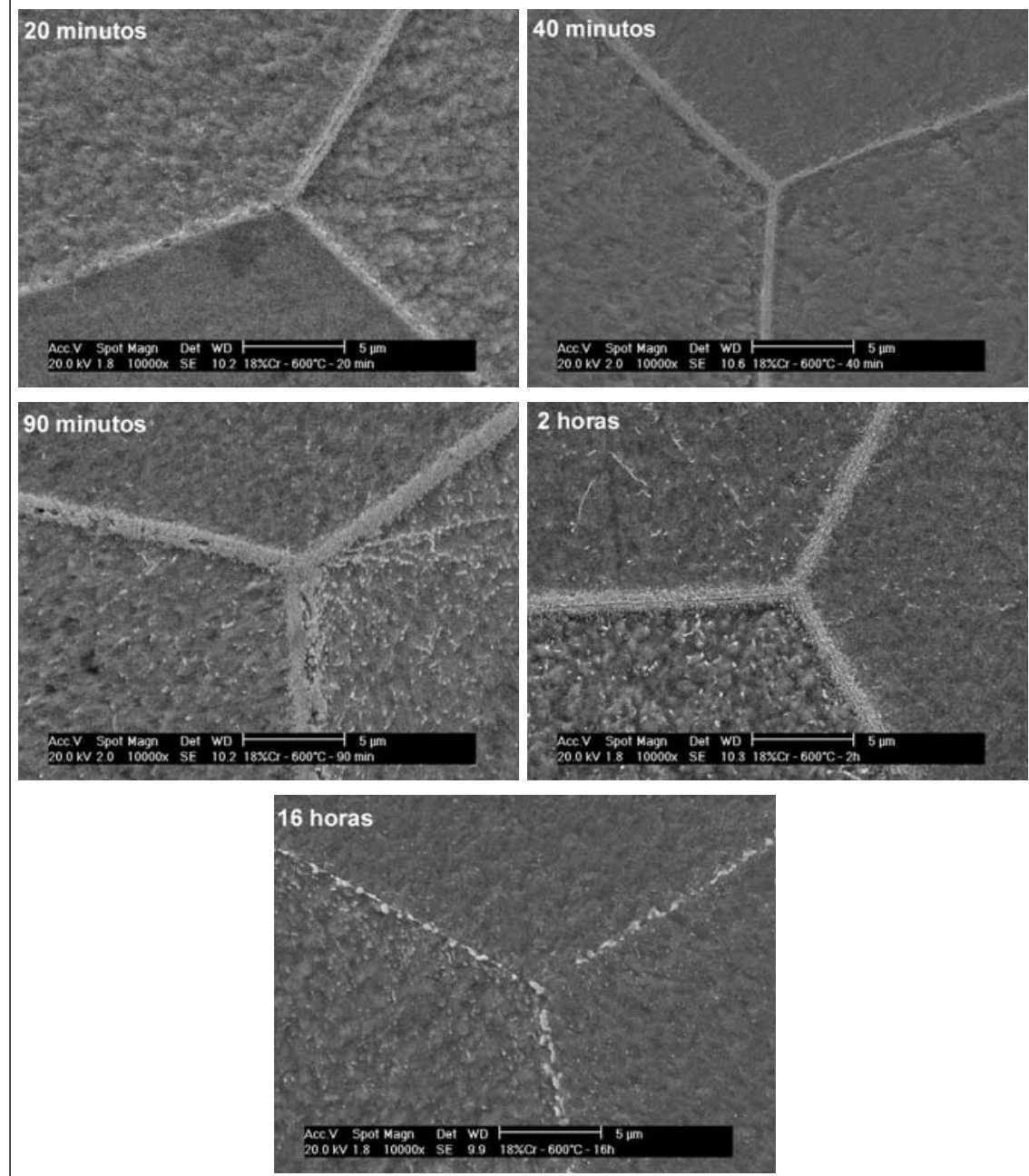

Figura 4 - Precipitados observados em MEV para o aço $\mathrm{Cr}-\mathrm{N}$ após solubilização e tratamento isotérmico a $600^{\circ} \mathrm{C}$. De 20 minutos a 2 horas, os contornos de grão são totalmente envolvidos pelos precipitados. Em 16 horas, os precipitados são mais grosseiros e mostram descontinuidade (coalescimento).

de cromo. Segundo Hodges (1971), o aumento no teor de cromo aumenta o fluxo desse elemento, o que acelera os processos de sensitização e recuperação. No presente trabalho, esse efeito do teor de cromo não foi observado, o que mostra que as diferenças de teor de cromo, entre os aços estudados, não interfiriram nas conclusões sobre o efeito dos elementos intersticiais.

O efeito do carbono, também, pode ser observado nos aços Cr-C-N $(0,040 \% \mathrm{C})$ e Cr-C (0,02\%C). Esses aços não só apresentam maior GS, em relação à condição solubilizada, como também apresentam maior velocidade de sensiti- zação para os tempos entre 5 e 20 minutos (Figura 3). O aumento no GS, para o aço Cr-C-N, deve-se, provavelmente, à disponibilidade do carbono na matriz ferrítica para continuar precipitando, principalmente como carboneto do tipo $\mathrm{M}_{23} \mathrm{C}_{6}$. Por outro lado, no aço Cr-N $(0,008 \%$ C e $0,0213 \% N)$, poder-se-ia esperar a precipitação de nitreto de cromo, $\mathrm{Cr}_{2} \mathrm{~N}$; no entanto, a estequiometria do nitreto envolve menor consumo de cromo do que a do carboneto; além disso, a solubilidade do nitrogênio é maior do que a do carbono (Honeycombe, 1982) e tais fatos explicariam a razão do maior tempo necessário para se atingir o máximo GS no aço Cr-N. 
Investigação do efeito do teor de intersticiais sobre o grau de sensitização em aços inoxidáveis...

\section{Conclusões}

Os aços inoxidáveis ferríticos com teores variáveis de carbono e nitrogênio (16\% Cr-0,04\% C-0,032\%N ; $17,2 \% \mathrm{Cr}-0,02 \% \mathrm{C}-0,0062 \% \mathrm{~N} ; 18,5 \% \mathrm{Cr}-0,008 \% \mathrm{C}-$ $0,0213 \% \mathrm{~N}$ ) são susceptíveis à corrosão intergranular após tratamento isotérmico realizado a $600^{\circ} \mathrm{C}$. O aumento no teor de carbono aumenta o valor máximo de grau de sensitização do aço. Por outro lado, o aumento do teor total de intersticiais $(\mathrm{C}+\mathrm{N})$ aumenta o tempo necessário para a obtenção do máximo grau de sensitização.

Tratamentos isotérmicos, por tempos maiores que 2 horas, melhoram, significativamente, a resistência à corrosão intergranular dos três aços estudados, ou seja, o tempo de tratamento de recuperação mostrou-se independente do teor total de intersticiais. Maiores tempos de tratamento isotérmico geram aglomeração e crescimento dos precipitados formados nos contornos de grão.

\section{Agradecimentos} a FEI.

Os autores agradecem a CAPES, a ANP, a ACESITA e

\section{Referências bibliográficas}

ALONSO-FALLEIROS, N. et alii. Intergranular corrosion in a martensitic stainless steel detected by electrochemical tests. Corrosion, v. 55, n. 8, p. 769-778, 1999.

ARAI, H. et alii. Theoretical analysis of susceptibility of ferritic stainless steel to intergranular corrosion caused by welding. Transaction of JWRI, v. 16, n. 1, p. 131-137, 1987.

BOND, A.P. Mechanism of intergranular corrosion in ferritic stainless steels. Transactions of the Metallurgical Society of AIME, v. 245, p. 2127-2134, 1969.

DEMO, J.J. Mechanism of high temperature embrittlement and loss of corrosion resistance in AISI type 446 stainless steel. Corrosion, v. 27, n. 12, p. 531-544, 1971.
FOLKHARD, E. Welding metallurgy of stainless steels. SpringerVerlag, 1988, p 103-110, 144-116, 125, 130, 178.

FRANKENTAL, R.P., PICKERING, H.W. Intergranular corrosion of a ferritic stainless steel. Journal Electrochemical Society, v. 120, n. 1, p. 23-26, 1973.

GORDON, W., VAN BENNEKOM, A. Review of stabilisation of ferritic stainless steels. Materials Science and Technology, v. 12, n. 2, p. 126-131, 1996.

HONEYCOMBE, R.W.K. Aços: microestrutura e propriedades. Fundação Calouste Gulbenkian, p. 16-18, 1982.

JACK, D.H., JACK, K.H. Invited review: carbides and nitrides in steel. Materials Science and Engineering, v. 11, p. 1-27, 1973.

LEE, J.B. et alii. An analytical electron microscope examination of sensitized AISI 430 stainless steel. Corrosion, v. 41, n. 2, p. 7680, 1985.

OGWU, A.A., DAVIES, T.J. Improving the sensitization resistance of ferritic stainelss steels. Scripta Materialia, v. 37, n. 3, p. 259263, 1997.

SERNA-GIRALDO, C.A. Resistência à corrosão intergranular do aço inoxidável ferrítico UNS S43000: avaliação por método de reativação eletroquímica, efeito de tratamento isotérmico $e$ mecanismo de sensitização. São Paulo: Escola Politécnica da Universidade de São Paulo, 2006. 197 p. (Tese de Doutorado),

STREICHER, M.A. The role of carbon, nitrogen and heat treatment in the dissolution of iron-chromium alloys in acids. Corrosion, v. 29, n. 9, p. 337-360, 1973.

TEODORO, C.A., WOLYNEC, S. Sensitization and tunneling corrosion of austenitic type 347 stainless steel. Corrosion, v. 54, n. 2, p. 121-128, 1998.

TOMARI et alii. Intergranular stress corrosion cracking of $13 \% \mathrm{Cr}$ and $18 \% \mathrm{Cr}$ ferritic stainless steels in high temperature high purity water. Corrosion, v. 38, n. 5, p. 283-294, 1982.

TULLMIN et alii. Intergranular corrosion in low intersticial $40 \% \mathrm{Cr}$ ferritic stainless steels. British Corrosion Journal, v 25, n. 3, p. 191-196, 1990.

VILLAFUERTE, J.C., KERR, H.W. Phase transformation in stainless steel weld metal and heat-affected zone. Key Engineering Materials, v. 69 e 70, p.129-148, 1992.

Artigo recebido em 30/07/2006 e aprovado em 05/10/2006.

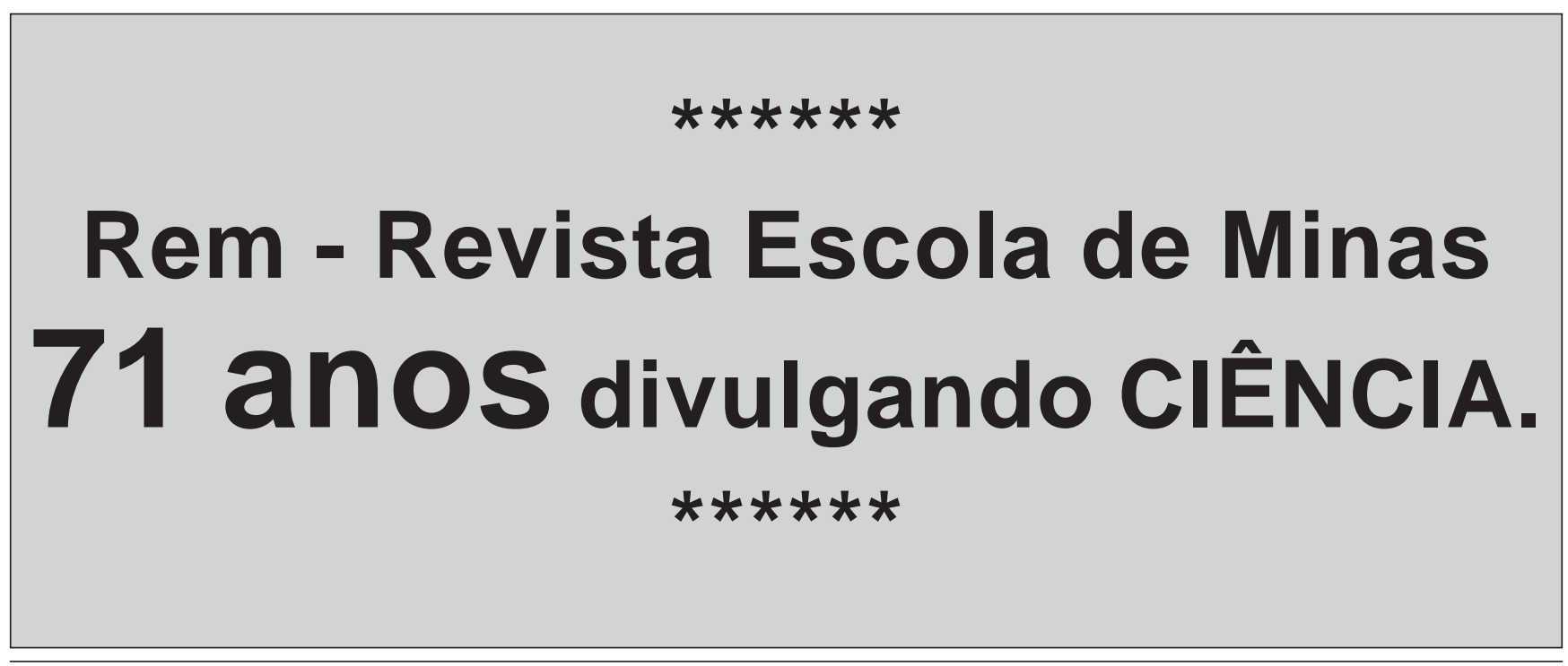

